\title{
An Improved Spatial-Temporal Downscaling Method for TRMM Precipitation Datasets in Alpine Regions: A Case Study in Northwestern China's Qilian Mountains
}

\author{
Lei Wang ${ }^{1,2}{ }^{\oplus}$, Rensheng Chen ${ }^{1, *}$, Chuntan Han ${ }^{1,2}{ }^{\text {, Yong Yang }}{ }^{1}$, Junfeng Liu ${ }^{1}$, Zhangwen Liu ${ }^{1}$, \\ Xiqiang Wang ${ }^{1}$, Guohua Liu ${ }^{1,2}$ and Shuhai Guo ${ }^{1,2}$ \\ 1 Qilian Alpine Ecology \& Hydrology Research Station, Key Laboratory of Ecohydrology of Inland River \\ Basin, Northwest Institute of Eco-Environment and Resources, Chinese Academy of Sciences, Lanzhou \\ 730000, China; sdwanglei@lzb.ac.cn (L.W.); hancht@lzb.ac.cn (C.H.); yy177@lzb.ac.cn (Y.Y.); \\ liujfzyou@lzb.ac.cn (J.L.); zwliu@lzb.ac.cn (Z.L.); wangxq@lzb.ac.cn (X.W.); lgh1990@lzb.ac.cn (G.L.); \\ guoshuhai@lzb.ac.cn (S.G.) \\ 2 University of Chinese Academy of Sciences, Beijing 100049, China \\ * Correspondence: crs2008@lzb.ac.cn
}

Received: 4 March 2019; Accepted: 6 April 2019; Published: 10 April 2019

\begin{abstract}
Remote sensing techniques provide data on the spatial-temporal distribution of environmental parameters over regions with sparse ground observations. However, the resolution of satellite precipitation data is too coarse to be applied to hydrological and meteorological research at basin scales. Downscaling research using coarse remote sensing data to obtain high-resolution precipitation data is significant for the development of basin-scale research. Here, we propose improvements to a spatial-temporal method for downscaling satellite precipitation. The improved method uses a nonlinear regression model and introduces longitude and latitude based on processed normalized difference vegetation index (NDVI) and a digital elevation model (DEM) to stimulate precipitation in the Qilian Mountains during 2006-2015. The final downscaled annual precipitation (FDAP) results are corrected by observed data to obtain corrected final downscaled annual precipitation (CFDAP) datasets. For temporal downscaling, monthly downscaled data are the corrected monthly ratio multiplied by the corresponding downscaled annual datasets. The results indicated that processed NDVI (PNDVI) reflected spatial precipitation patterns more accurately than the original NDVI. The accuracy was significantly improved when the final downscaled annual precipitation data were corrected by observed data. The average annual root mean square error (RMSE) from 2006 to 2015 of CFDAP was 66.48 and $83.07 \mathrm{~mm}$ less than that of FDAP and original Tropical Rainfall Measuring Mission (TRMM) data, respectively. Compared with previous methods, which use NDVI and/or DEM to downscale TRMM, the accuracy of FDAP and CFDAP from the improved method was higher, and the RMSE decreased on average by 13.63 and $80.11 \mathrm{~mm}$. The RMSE of monthly data from corrected monthly ratio (CMR) decreased on average by $4.93 \mathrm{~mm}$ over monthly data from previous monthly ratio (PMR). In addition, the accuracy of the original satellite data affected the initial downscaling results but had no significant effects on the corrected downscaling results.
\end{abstract}

Keywords: improved downscaling method; TRMM precipitation datasets; processed NDVI; DEM; alpine mountains

\section{Introduction}

Precipitation is a key meteorological input parameter in various types of models because it affects land surface processes. Precipitation data for hydrological models are usually obtained by interpolation 
of sparse measurements. However, precipitation gauges are usually located at low elevations or in river valleys in mountainous areas, with high elevations sparsely or not at all represented, and measurement efforts are limited by harsh environment and funds. Moreover, precipitation gauges are distributed in such a way as to meet the practical requirements of national meteorological services rather than scientific requirements [1]. Clearly, biased positioning of precipitation gauges cannot sufficiently express the complex distribution of precipitation, particularly in alpine areas [2]. Therefore, reliable spatial information on precipitation is difficult to find [3].

The development of satellite remote sensing and data assimilation has proven promising in the estimations of global gridded precipitation [4,5]. However, current satellite-based precipitation products are available only at spatial resolutions of $0.05^{\circ}$ (about $5.6 \mathrm{~km}$ near the equator) or lower; examples are the Climate Hazards Group Infrared Precipitation with Station $\left(\mathrm{CHIRPS}, 0.05^{\circ} \times 0.05^{\circ}\right)$, Global Precipitation Measurement (GPM, $\left.0.1^{\circ} \times 0.1^{\circ}\right)$, Tropical Rainfall Measuring Mission $(\mathrm{TRMM}$, $\left.0.25^{\circ} \times 0.25^{\circ}\right)$, Climatic Research Unit precipitation datasets (CRU, $0.5^{\circ} \times 0.5^{\circ}$ ), and ERA-Interim precipitation datasets $\left(\mathrm{ERA}, 0.125^{\circ} \times 0.125^{\circ}\right)$. Although the spatial distribution of precipitation may be obtained from these datasets, their resolutions are too coarse to apply in hydrological research at a local or basin scale. Recent studies indicated that the spatial resolution of precipitation datasets greatly influences model outcomes, and that hydrological models using raster-based precipitation datasets outperform models that use precipitation from sparse rain gauges [6,7]. Therefore, various downscaling methods have been developed during the past decade. These studies explored the relationships between precipitation and various elements of the environment to obtain data at higher resolutions. Immerzeel et al. [8] obtained annual precipitation data at a high resolution ( 1000 m) by establishing exponential relationships between the normalized difference vegetation index (NDVI) and precipitation from TRMM datasets of different resolutions. Jia et al. [9] added elevation to Immerzeel's methods and showed that a multiple linear regression model can downscale TRMM data for the Qaidam Basin in northwest China. Retalis et al. [10] introduced DEM and NDVI into the artificial neural networks and obtained downscaled CHIRPS precipitation datasets on annual and monthly scale for Cyprus. Zhang et al. [11] introduced the elevation of maximum precipitation into the downscaling model, and the downscaled results are better than multiple linear regression models, exponential regression models and geographically weighted regression models in Three-Rivers Headwater Regions. Alexakis et al. [12] compared the multiple linear regression TRMM downscaling results with artificial neural networks, and the results show that the accuracy of the two downscaling results have different advantages in different months. However, there is a strong spatial heterogeneity in the relationships between precipitation and various geographical factor or land surface characteristics. Therefore, the geographically-weighted regression method and moving window regression $[13,14]$ were proposed based on the assumption that non-stationary relationships between precipitation and environmental variables (NDVI and/or DEM) vary across space. Zhan et al. [15] compared the accuracy of monthly downscaling results of multiple regression and geographically-weighted regression based on GPM, and the results show that geographically-weighted regression outperformed multiple regression models in the Hengduan Mountains. Recently, researchers have tried to construct the precipitation-variables relationships with different land surface characteristics as explanatory variables, examples are land surface temperature, longitude, and latitude [16-18]. Generally, the precipitation is affected by land surface characteristics, geographical factors, and sources of water vapor. Research showed that in a large study area, the impact of water vapor sources on precipitation needed to be considered [19]. The latitude and longitude were introduced into the statistical model to indicate the distance from the study area to a source of vapor, which is more accurate than the model that only considers geographical factors $[18,20]$.

These earlier studies achieved satisfactory results in different study areas based on relationships between precipitation and NDVI and /or other environment variables. A significant positive or exponential correlation was assumed between precipitation and NDVI in many studies, since precipitation provided water for plant growth $[8,9,21,22]$. In fact, this hypothesis has some limitations, 
as plant growth is the result of both water and heat effects, and it is not appropriate for regions with high precipitation and low temperatures [23]. Generally, precipitation increases with increased elevation in a certain range in mountainous areas; but NDVI first increases to a maximum value with the increased elevation, and then decreases because of the influence of temperature and precipitation [24]. For example, on mountain tops, precipitation is usually greater than at the foothills. Yet, mountain tops are usually regions with sparse plant growth affected by temperatures. Therefore, the effects of temperature on NDVI need to be removed when using NDVI as a variable in a statistical analysis of precipitation in mountains areas. Two steps were necessary before the models were built. First, the impact of temperature on the original NDVI has to be removed to obtain processed NDVI (PNDVI). Second, the distribution of precipitation in Qilian Mountains has distinct longitude/latitude-belt distribution characteristics according TRMM precipitation datasets and Liu et al. [19]. Therefore, the longitude and latitude were used in the models to indicate the distance from the study area to a source of vapor based on PNDVI and DEM. Next, statistical models were built for each individual year from 2006 to 2015 based on the relationships between annual TRMM precipitation and geographical and environmental variables, with subsequent downscaling of the annual TRMM data.

Here, we introduce an improved downscaling method for TRMM precipitation datasets for alpine areas based on previous studies $[8,9,14]$. The two objectives of the study are as follows: (1) To obtain high resolution $(\sim 1000 \mathrm{~m})$ annual precipitation data from relationships between coarse annual TRMM measurement datasets and multiple land surface characteristics for the Qilian Mountains; (2) get the high resolution $(\sim 1000 \mathrm{~m})$ monthly precipitation data by the improved methods based on previous study proposed by Duan et al. [25].

\section{Study Areas}

The Qilian Mountains (Figure 1) are located at the northeastern margin of the Tibetan Plateau, mainly in Qinghai and Gansu Provinces; they span approximately $850 \mathrm{~km}$ from west to east and $300 \mathrm{~km}$ from north to south. The mountain range has a wide elevational gradient [26] from $1450 \mathrm{~m}$ to $5800 \mathrm{~m}$ with approximately $35 \%$ of the area at $>3500 \mathrm{~m}$. The average annual temperature in the Qilian Mountains was $-2.38{ }^{\circ} \mathrm{C}$ from 2006 to 2015 (data from measurement datasets in the study). Three main atmospheric circulation patterns affected the Qilian Mountains-the Westerly, the Plateau monsoon, and the East Asian monsoon [27-29]. The average annual precipitation from 1960 to 2004 was $403.6 \mathrm{~mm}$ /year (data from measurement datasets, [30]). Eighty-four percent of the precipitation was concentrated in the wet season (May to September; from 2006 to 2015), affected mainly by the Asian monsoon.

The main vegetation types of the Qilian Mountains are grass, Qilian spruce (Picea crassifolia), mainly on shady slopes, and sparse Qilian juniper (Sabina przewalskii Kom), mainly on sunny slopes [31]. The growing season lasts from May to August, and its length is affected by precipitation and temperature [32]. The land cover types in the Qilian Mountains are desert steppe, steppe, forest, alpine meadow, and Moraine-talus, respectively, from low to high elevations. Plant cover becomes denser, first from low to middle elevation, and then becomes sparser with increasing elevation, decreasing temperature, and the changing characteristics of precipitation. These trends introduce a temperature-related error when NDVI is used to indicate the amount of precipitation in mountainous areas, necessitating a correction. 


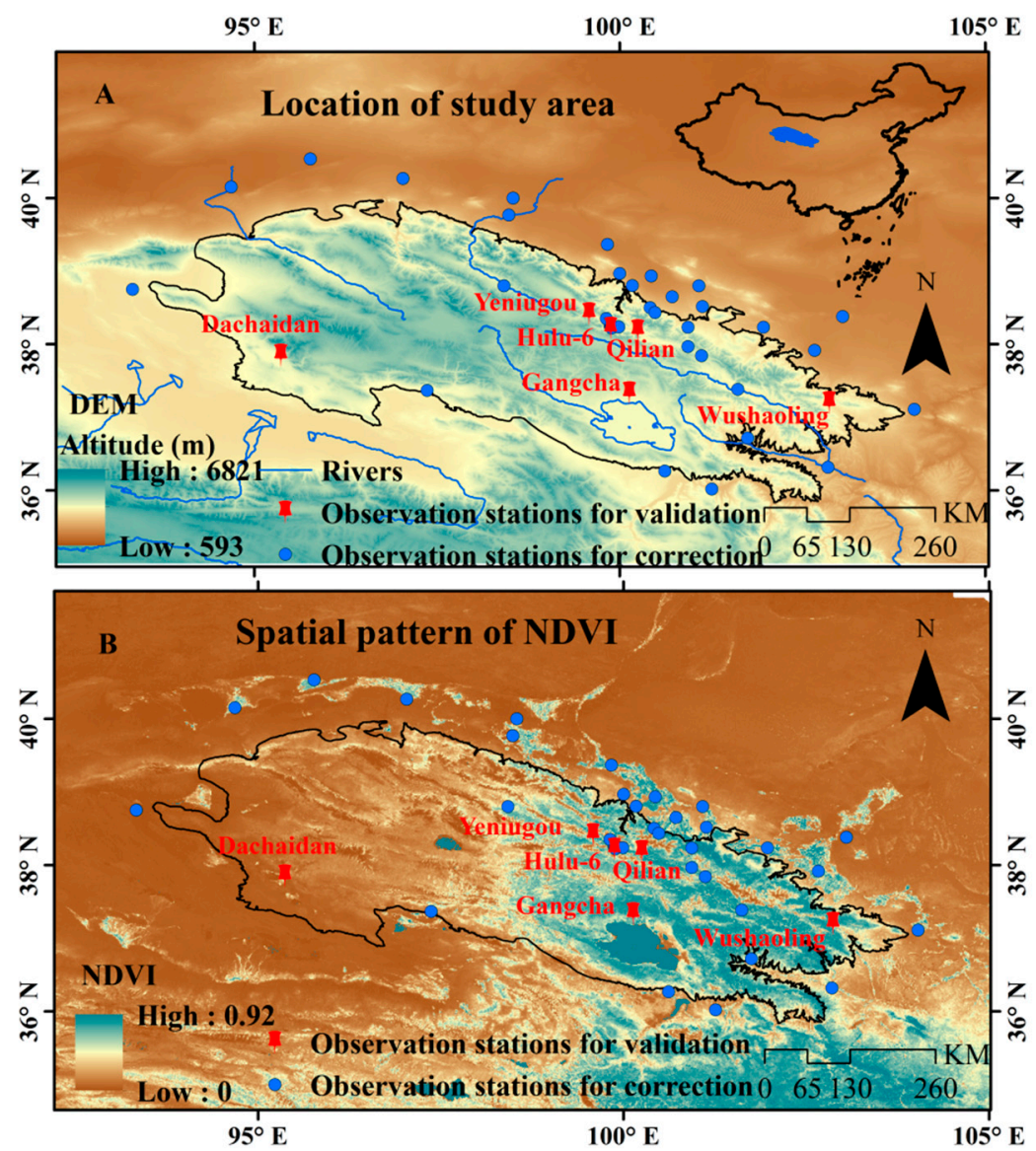

Figure 1. Distribution of observation stations for correction (blue dots, 34 stations) and validation (red pins, 6 stations) stations (A) and spatial pattern of normalized difference vegetation index (NDVI) (B) in study area.

\section{Datasets and Methodology}

\subsection{Datasets}

\subsubsection{Point Observation Data}

Datasets used in this study included precipitation measured in 40 gauges and temperature taken at $2 \mathrm{~m}$-height; they were provided by the National Climatic Centre of the China Meteorological Information Center (http://data.cma.cn/) and Cold and Arid Regions Science Data Center (http: //westdc.westgis.ac.cn). Precipitation-gauge and temperature datasets were checked for data quality and homogeneity of variances. The grid temperature datasets used in the study were obtained by interpolating between temperature values from the study area and those from the nearest meteorological stations. The interpolated results in each year passed the $p<0.001$ significance test. We used the Min-Max Normalization method [33] for the normalization of temperature data.

\subsubsection{TRMM}

The TRMM satellite was launched in November 1997. It was designed to improve the understanding of the variability and distribution of precipitation in tropical and sub-tropical regions. The datasets utilized in this study were TRMM 3B43 V7 products from January 2006 to December 2015, which provided monthly precipitation data at a spatial resolution of $0.25^{\circ} \times 0.25^{\circ}$, and covering $50^{\circ}$ $\mathrm{N} \sim 50^{\circ}$ S. The datasets were downloaded from National Aeronautic and Space Administration (NASA) Precipitation Measurement Mission website: https://pmm.nasa.gov/data-access. 


\subsubsection{NDVI Datasets}

NDVI is an indicator used to measure vegetative production. Compared with precipitation datasets, a series of NDVI products has been published with high spatial resolutions $(\sim 1000 \mathrm{~m})$. We used the MOD13A3 monthly NDVI product at $1000 \mathrm{~m}$ spatial resolution in this study, obtained from http:/ / modis-land.gsfc.nasa.gov/vi.html. First, the maximum NDVI value for each month was acquired using the maximum-value-composites method $[9,25,34]$ to eliminate atmospheric and cloud cover effects. Next, monthly average NDVI values during May-September of each year were computed as a proxy index for vegetation growth during the growing season and used in annual datasets.

\subsubsection{Digital Elevation Models}

Digital elevation models (DEMs) data were obtained from the Shuttle Radar Topography Mission (RTM), an international project launched by the National Geospatial-Intelligence Agency (NGA) and National Aeronautics and Space Administration (NASA). The project provided high resolution DEMs datasets for latitudes between $60^{\circ} \mathrm{N} \sim 50^{\circ} \mathrm{S}$ at high spatial resolutions. Only the $90-\mathrm{m}$ DEM datasets were needed in this study and were downloaded from http:/ / www2.jpl.nasa.gov/srtm/; the $1000 \mathrm{~m}$ data were obtained by resampling. Other variables (elevation, longitude, latitude) used in the study were calculated from the $1000 \mathrm{~m}$ DEM datasets.

\subsection{Methodology}

\subsubsection{Downscaling}

The methodology used in the research was developed, applied by Agam et al [35], Immerzeel et al [8], and Jia et al. [9]. Agam et al. [35] proposed a downscaling technique for spatial focusing of imagery based on the vegetation index. Immerzeel et al. [8] applied the methodology by selecting the statistical downscaling model at an optimum resolution (at $0.75^{\circ} \times 0.75^{\circ}$ scale), applied it to downscaling of TRMM precipitation data, and by interpolating the residuals for Iberian Peninsula in Spain. Jia et al. [9] introduced elevation to the methodology for downscaling of TRMM. However, precipitation is usually affected by elevation and location (latitude and longitude) in mountainous areas [28,36-40]. Therefore, we introduced longitude and latitude based on PNDVI and DEM as variables for downscaling. To remove the impact of temperature on NDVI, we introduced the following index to characterize hydro-thermal conditions.

$$
P T=\text { Pre } \times \text { Tem }
$$

where PT was a hydro-thermal index, Pre was normalized precipitation and Tem was normalized temperature obtained by Min-Max Normalization method. We assumed that plant growth was proportional to $P T$, as follows:

$$
\text { NDVI } \propto P T
$$

Further derived from formula (2):

$$
P N D V I=\frac{N D V I}{T e m} \propto \text { Pre }=\frac{P T}{T e m},
$$

where PNDVI was NDVI with the effect of temperature removed. Further research used PNDVI instead of the original NDVI data in the downscaling process. The models were multiple nonlinear models, as follows:

$$
P_{\text {TRMM }}=a_{1} * \text { PNDVI }+b_{1} * \text { ele }+c_{1} * l o n+d_{1} * l a t+e_{1} * l o n^{2}+f_{1} * l a t^{2}+g_{1}
$$


where $P_{\text {TRMM }}$ was the annual precipitation obtained from TRMM, and $a_{1}, b_{1}, c_{1}, d_{1}, e_{1}, f_{1}$ were coefficients of the corresponding variables ele, lon, lat, which were elevation, longitude, and latitude, respectively; $g_{1}$ was a constant. The specific downscaling processes in Figure 2 were as follows:

(1) Preparation of the original data such as DEM $(1000 \mathrm{~m})$, TRMM monthly $\left(0.25^{\circ} \times 0.25^{\circ}\right)$, NDVI (1000 m), and observed monthly temperature and precipitation from 2006 to 2015;

(2) Calculation of grid temperature $(1000 \mathrm{~m})$ from the statistical relationships between temperature and elevation, longitude, latitude (Specific steps are omitted). Normalization of temperature data with the Min-Max Normalization method and dividing the original NDVI by the normalized temperature at the resolution $1000 \mathrm{~m}$, then, obtaining the PNDVI from simple spline tension interpolator.

(3) Resampling to acquire various variables at $0.25^{\circ}$ resolution, including DEM (elevation, latitude and longitude) and PNDVI.

(4) Establishing of multiple nonlinear regression models for each year from 2006 to 2015 at $0.25^{\circ}$ scale using PNDVI, elevation, longitude, and latitude.

(5) Prediction of annual precipitation at $0.25^{\circ}$ scale with multiple nonlinear regression models. Then, subtracting of the predicted annual data from the original annual TRMM data to obtain the residuals of the models.

(6) Model application at the $1000 \mathrm{~m}$ scale for each year and prediction of annual precipitation at $1000 \mathrm{~m}$. Then, interpolation of the residuals to $1000 \mathrm{~m}$ scale using the spline tension method. The residuals at $1000 \mathrm{~m}$ are added to the predicted annual precipitation at $1000 \mathrm{~m}$ scale each year to obtain the final downscaled annual precipitation (FDAP, without correction by observed precipitation data).

(7) Correction of the FDAP by establishing relationships between the observed annual precipitation and FDAP, PNDVI, elevation, longitude, and latitude at $1000 \mathrm{~m}$ scale to obtain the corrected final downscaled annual precipitation (CFDAP, corrected by 34 observation stations datasets). The following formula was used:

$$
P_{o}=a_{2} * P_{d}+b_{2} * P N D V I+c_{2} * \text { ele }+d_{2} * \text { lon }+e_{2} * l a t+f_{2} * l o n^{2}+g_{2} * a l t^{2}+h_{2}
$$

where $P_{o}$ and $P_{d}$ were observed precipitation and FDAP, and $a_{2}, b_{2}, c_{2}, d_{2}, e_{2}, f_{2}$ and $g_{2}$ were coefficients of the corresponding variables, and ele, lon, lat were elevation, longitude and latitude, respectively; $h_{2}$ was a constant.

For temporal downscaling, the previous monthly ratio (PMR, without correcting) was obtained from dividing the monthly TRMM precipitation by the original annual TRMM precipitation [25]. The corrected monthly ratio (CMR) can be obtained from the statistical relationships between the observed monthly ratio and the ratio from TRMM datasets, annual TRMM precipitation, elevation, longitude, and latitude. Next, the interpolation of the corrected ratios to $1000 \mathrm{~m}$ scale using the spline tension method. The corrected ratio is multiplied by the corrected final downscaled annual precipitation to obtain monthly precipitation data for each year. The following formula was used:

$$
R_{o}=a_{3} * R_{T}+b_{3} * \text { TRMM } M_{\text {annual }}+c_{3} * \text { ele }+d_{3} * \text { lon }+e_{3} * \text { lat }+f_{3} * \operatorname{lon}^{2}+g_{3} * a l t^{2}+h_{3}
$$

where $R_{o}$ and $R_{T}$ were monthly ratios obtained from dividing the observed monthly data by annual data or dividing the monthly TRMM precipitation by the original annual TRMM precipitation, respectively. $T R M M_{\text {annual }}$ was annual TRMM precipitation. Other variables were the same as in formula (5).

Important issues in the building of multiple nonlinear models involved areas devoid of vegetation and others, where plants were not influenced by precipitation. Such areas included Qinghai Lake, most hilltops, and farmland. To address this, these areas were eliminated according to land-use type, and the annual precipitation in these regions was interpolated from downscaled datasets around them. 
A

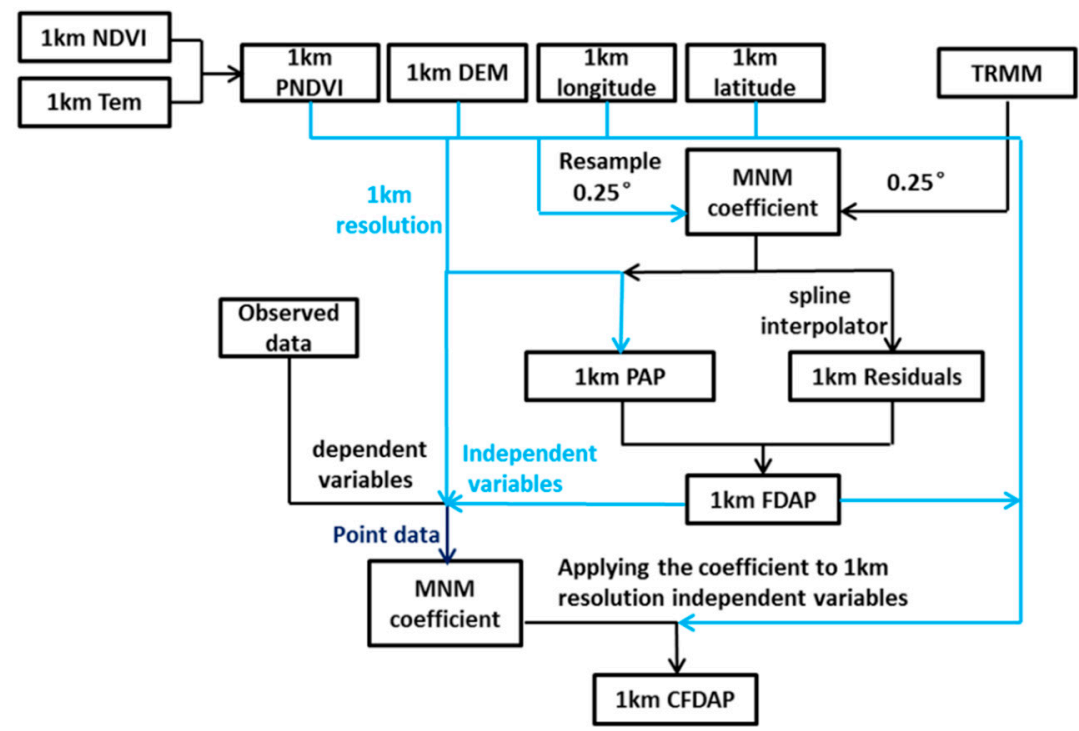

B

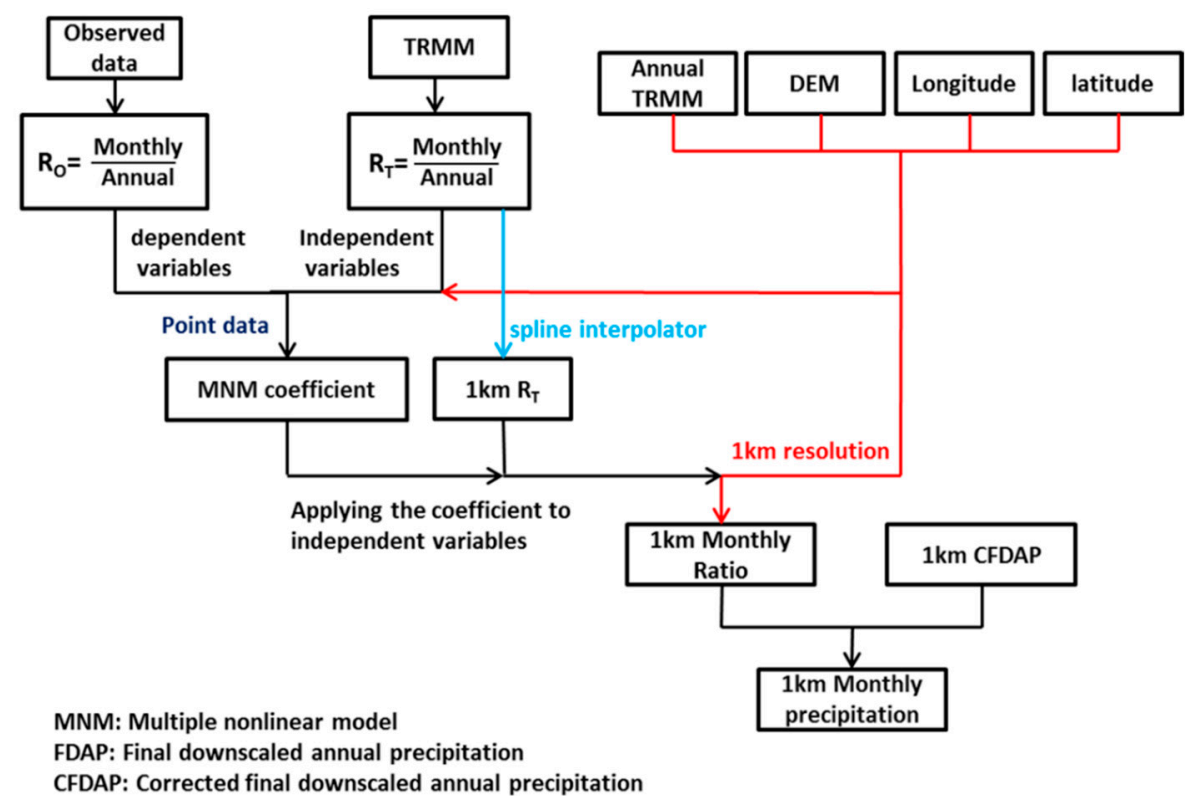

Figure 2. The flow chart of the annual Tropical Rainfall Measuring Mission (TRMM) data downscaling algorithm (A) and monthly TRMM data downscaling algorithm (B) proposed in this study.

\subsubsection{Validation}

The results of downscaling, including annual and monthly precipitation, were validated using observed values (6 observation stations, Figure 1; Table 1). The accuracy of various downscaling results was tested with the following:

Bias (B), expressed as:

$$
\mathrm{B}=\frac{\sum_{\mathrm{i}=1}^{\mathrm{n}} \mathrm{P}_{\mathrm{i}}}{\sum_{\mathrm{i}=1}^{\mathrm{n}} \mathrm{O}_{\mathrm{i}}}-1
$$


The root mean square error (RMSE), expressed as:

$$
\text { BRMSE }=\sqrt{\left(\frac{\sum_{\mathrm{i}}^{\mathrm{n}}\left(\mathrm{O}_{\mathrm{i}}-\mathrm{P}_{\mathrm{i}}\right)^{2}}{\mathrm{n}}\right)}
$$

Nash-Sutcliffe efficiency coefficient (NSE), expressed as:

$$
\mathrm{NSE}=1-\frac{\sum_{\mathrm{i}}^{\mathrm{n}}\left(\mathrm{O}_{\mathrm{i}}-\mathrm{P}_{\mathrm{i}}\right)^{2}}{\sum_{\mathrm{i}}^{\mathrm{n}}\left(\mathrm{O}_{\mathrm{i}}-\overline{\mathrm{O}}\right)^{2}}
$$

In the three formulas (7) (9), where $P_{i}$ and $O_{i}$ were predicted data and observed data, the $\bar{O}$ is the average of the observed data.

Table 1. Characteristics of the validation measurement points.

\begin{tabular}{ccccccc}
\hline Station Name & Longitude & Latitude & Elevation $(\mathbf{m})$ & Land Cover & $\begin{array}{c}\text { Mean Annual } \\
\text { Precipitation (mm) }\end{array}$ & $\begin{array}{c}\text { Mean Annual } \\
\text { Temperature }\left({ }^{\circ} \mathbf{C}\right)\end{array}$ \\
\hline Qilian & 100.25 & 38.18 & 2787.4 & Steppe and forests & 411.5 & 1.18 \\
Wushaoling & 102.87 & 37.20 & 3045.1 & Steppe and Forests & 402.7 & 0.37 \\
Dachaidan & 95.37 & 37.85 & 3173.2 & Bare soil & 89.4 & 388.4 \\
Gangcha & 100.13 & 37.33 & 3301.5 & Steppe & 420.6 & 0.04 \\
Yeniugou & 99.58 & 38.42 & 3320.0 & Steppe & 762.6 & -0.39 \\
Hulu-6 & 99.88 & 38.22 & 4484.0 & Moraine-talus & -7.2 & \\
\hline
\end{tabular}

\section{Results}

\subsection{Downscaling Procures}

Before the establishment of multiple nonlinear regression models, the NDVI was corrected for the temperature effect (Figure 3, 2010 taken as an example to indicate the downscaling procures). The spatial distribution of plants after correction changed significantly. Namely, plant density became greater on mountain tops and in alpine areas where plants were sparsely distributed before the correction (Figure 3B,C). Simultaneously, the precipitation-PNDVI relationship improved over that of precipitation-NDVI (Figure 4).

The multiple nonlinear regression models depended on parameterization in different years. Therefore, the choice of optimal parameters for each individual year was important. Therefore, necessary parameters and residuals were obtained according to steps (3), (4), and (5) of the procedures (Figure 5A) based on the statistical relationships between precipitation and PNDVI, DEM, longitude, latitude in each individual year. The low resolution residuals were interpolated to $1000 \mathrm{~m}$ with simple spline-tension interpolation (Figure 5B). 


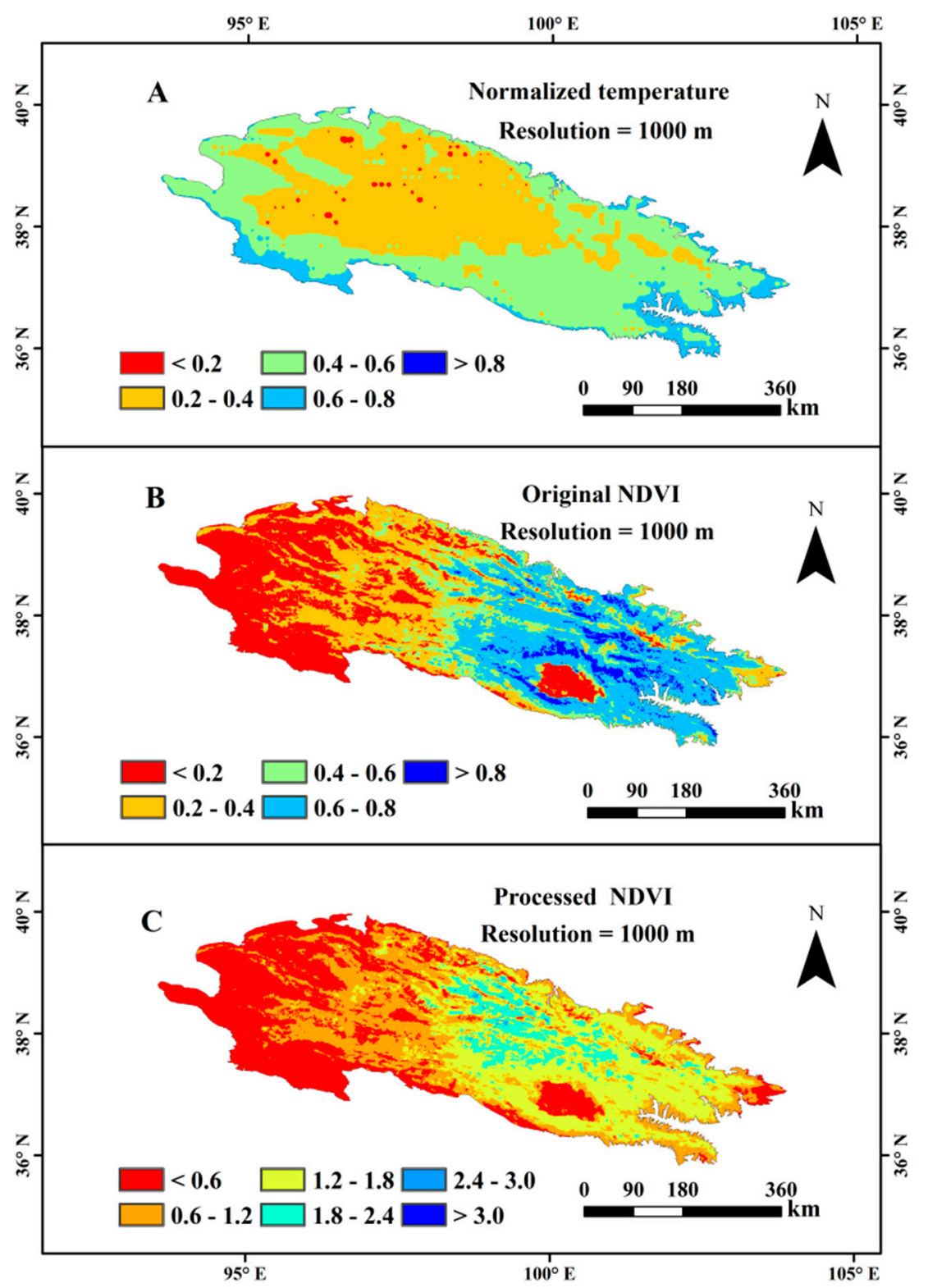

Figure 3. The normalized temperature (A) and original normalized difference vegetation index (NDVI) (B), and processed NDVI (C) in 2010.
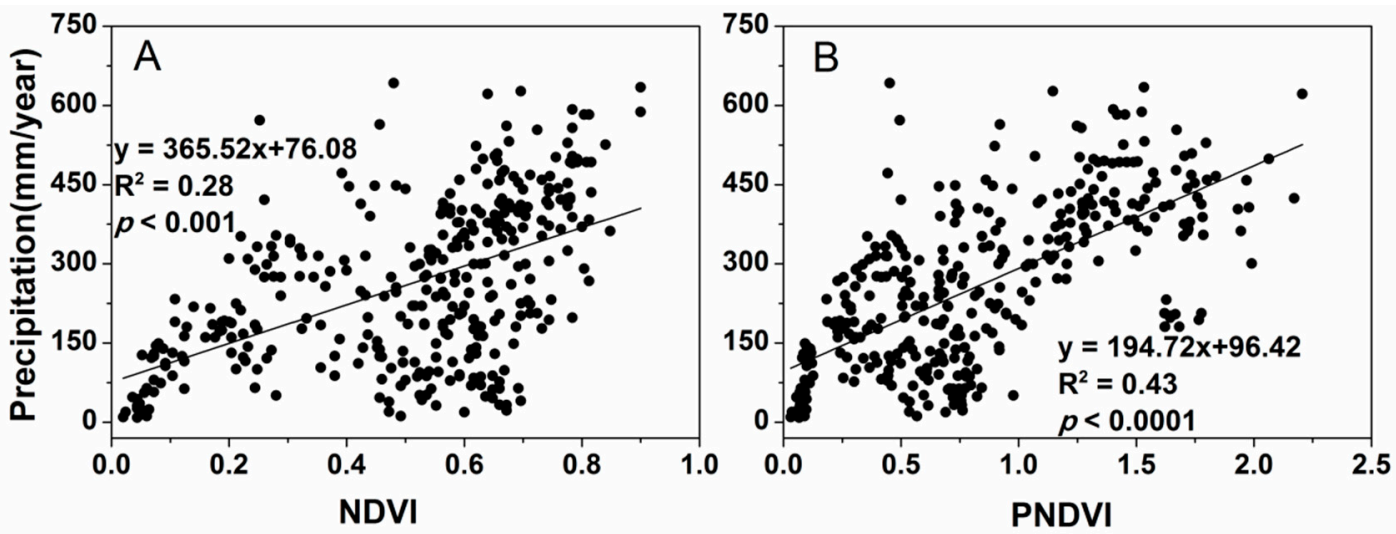

Figure 4. The scatter diagram between annual precipitation and NDVI (A) and processed NDVI (PNDVI) (B). 


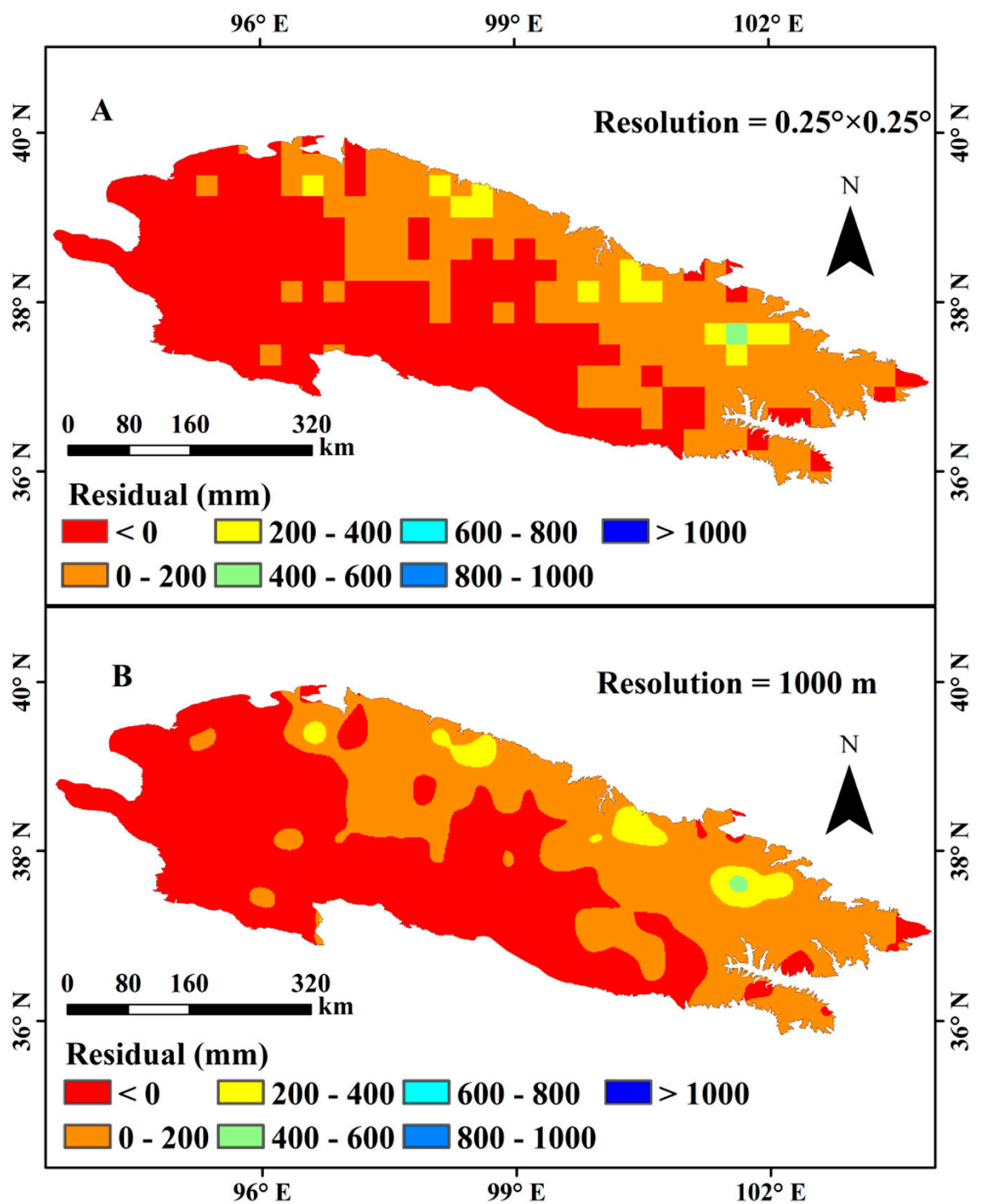

Figure 5. The residuals at coarse resolution $\left(\mathbf{A}, 0.25^{\circ}\right)$ and high resolution $(\mathbf{B}, 1000 \mathrm{~m})$ in 2010.

Then, by applying the regression models to PNDVI and other variables with the $1000 \mathrm{~m}$ resolution, we obtained the predicted annual precipitation at $1000 \mathrm{~m}$ scale according to step (6) (Figure 6B). The predicted precipitation was significantly lower than the original annual precipitation obtained from TRMM data (Figure 6A). Despite adding the 1000-m scale residuals to the predicted annual precipitation (FDAP; Figure 7A), there was still an inaccuracy in FDAP compared with the observed precipitation data. Therefore, the FDAP needs further correction by observed data. After correction according to step (7), CFDAP was obtained (Figure 7B). At a monthly scale, previous studies [13,25] use the PMR multiplied by the corresponding downscaled annual precipitation to obtain downscaled monthly precipitation (Figure 8A, take August 2010 as an example). The monthly precipitation data obtained by the above method is not accurate enough to apply in other research (Figure 9A). It still needs to be corrected by observed data, corrected step shown as step (8). After step (8), the final CMR (Figure 8B) and monthly precipitation was obtained (Figure 9B). 


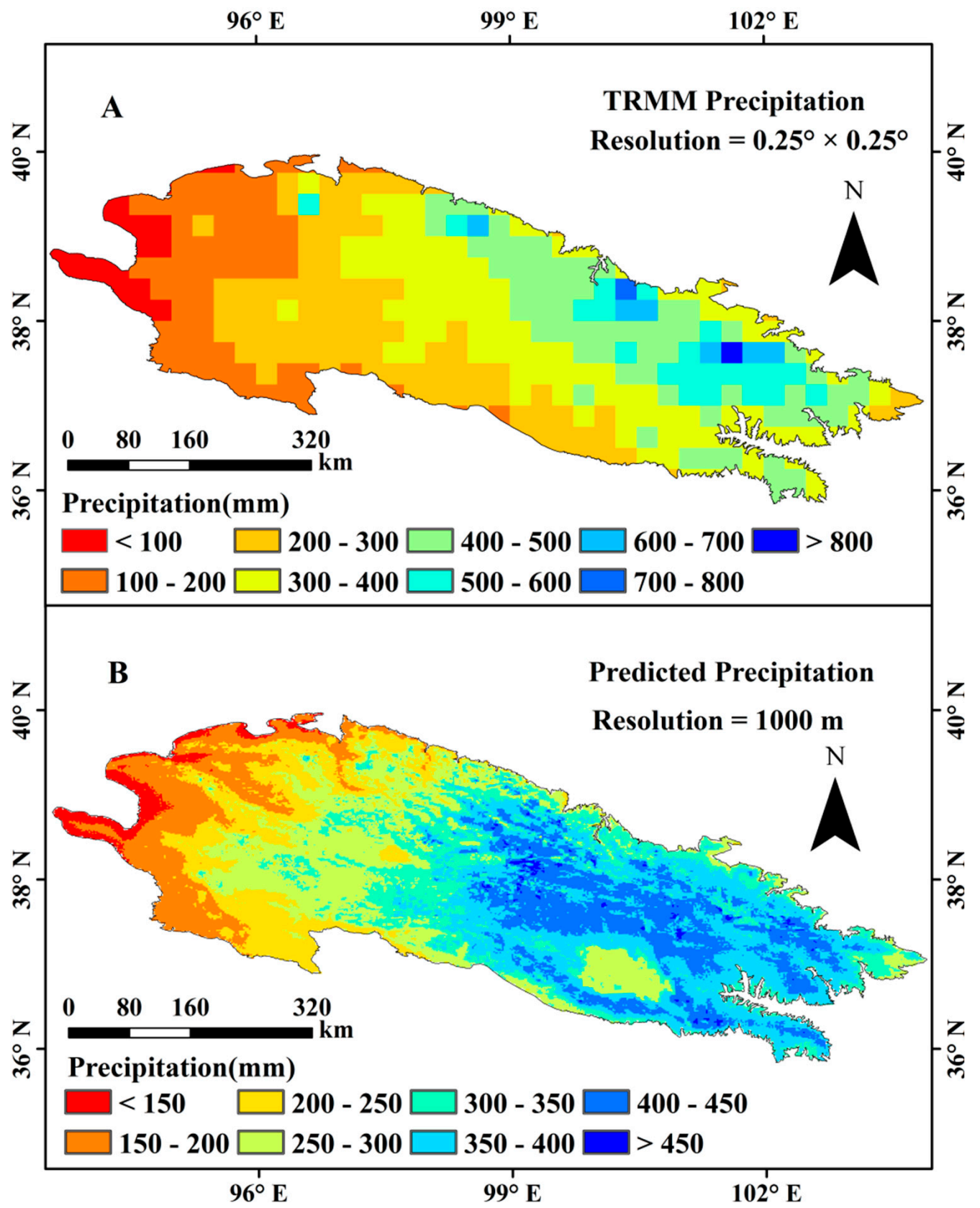

Figure 6. Spatial distribution of precipitation from original TRMM (A) and predicted precipitation (B) in 2010. 


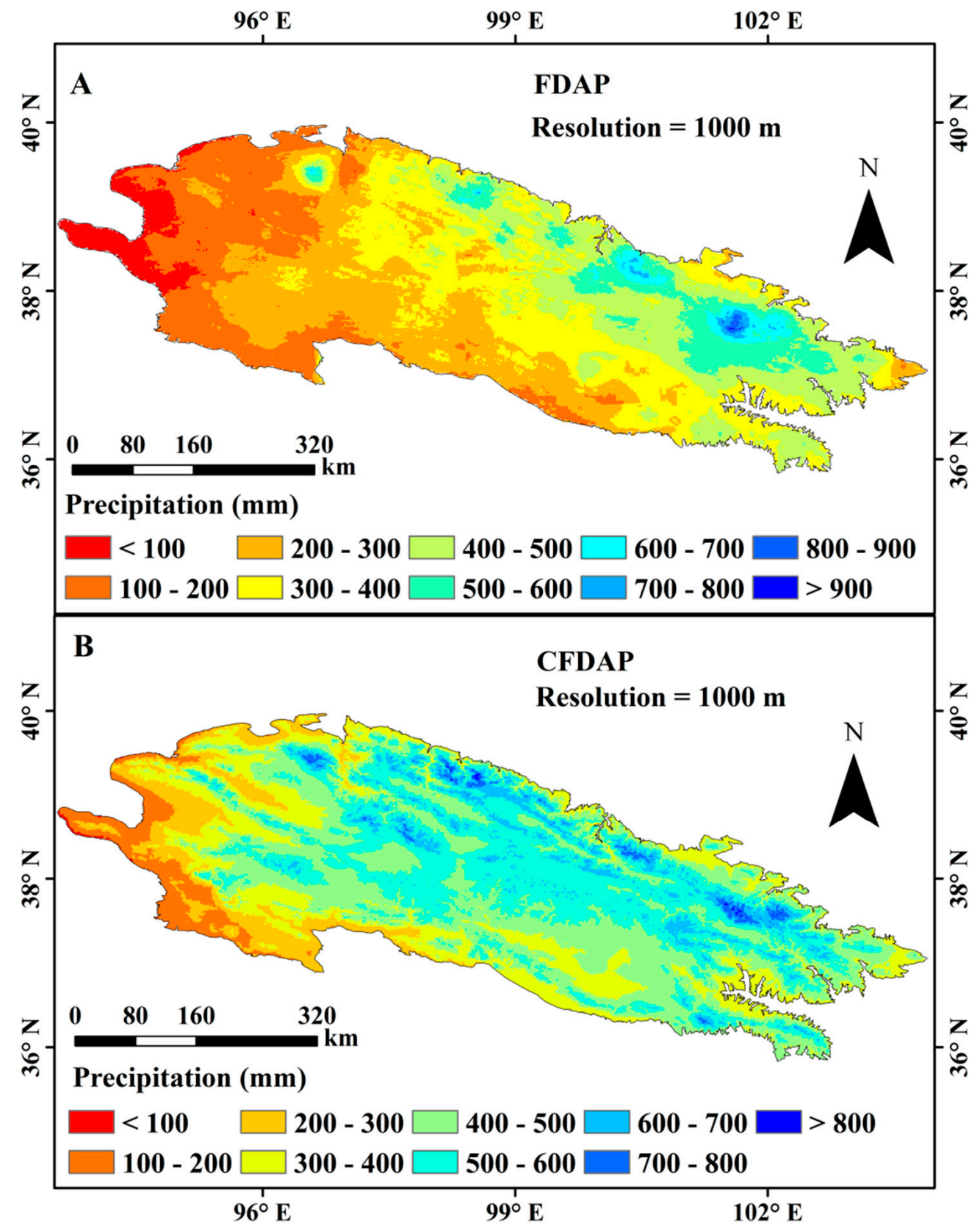

Figure 7. Comparison of final downscaled annual precipitation (FDAP) (A) and corrected final downscaled annual precipitation (CFDAP) (B) in 2010. 


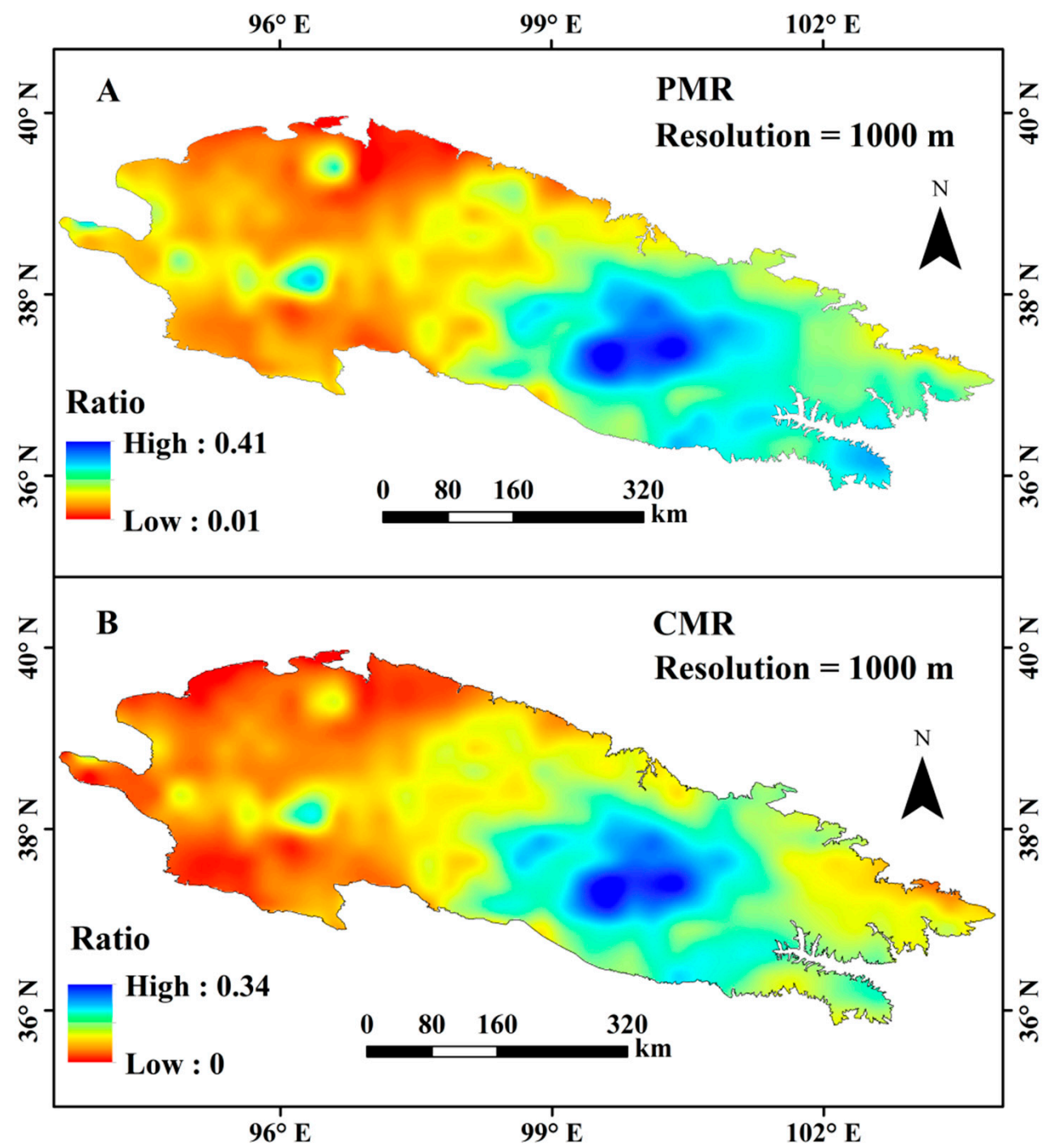

Figure 8. Comparison of previous monthly ratio (PMR) (A) and corrected monthly ratio (CMR) (B) in August 2010. 


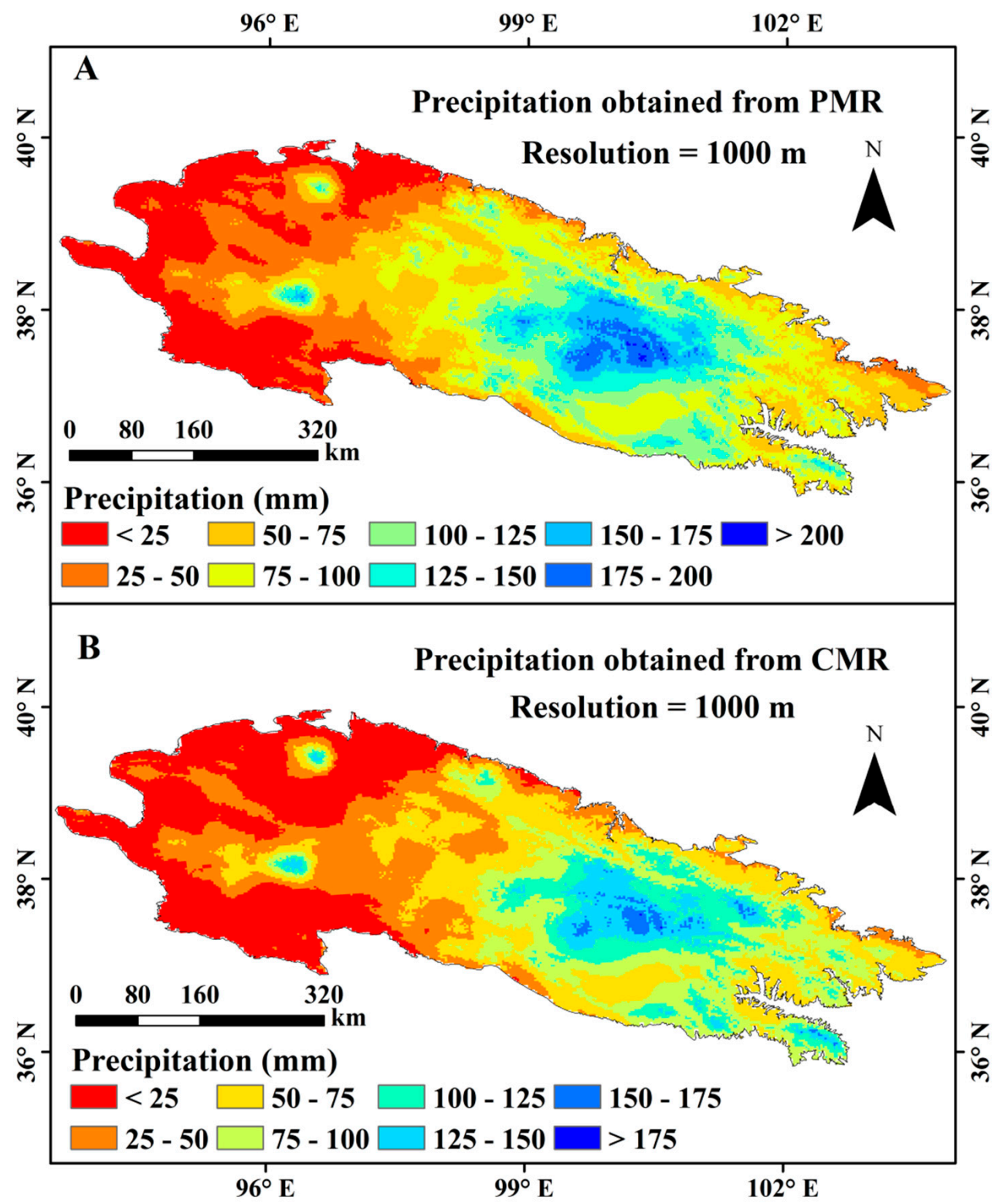

Figure 9. Comparison of August precipitation obtained from PMR (A) and from CMR (B) in 2010.

\subsection{Downscaled Annual Precipitation and Validation}

To quantitatively evaluate the accuracy of original annual TRMM data, FDAP and CFDAP are compared with observed datasets from 2006 to 2015. The statistic results are shown in Table 2. The FDAP are more accurate than the original TRMM data when compared to the overall error statistics from 2006 to 2015. The average RMSE of FDAP decreased about $16.58 \mathrm{~mm}$ than that of the original TRMM data from 2006 to 2015. The distribution characteristics of TRMM and FDAP were consistent, that is, precipitation decreased gradually from northeast to southwest (Figures 6 and 7). The spatial pattern of precipitation was the same as that in previous studies [19], but the errors were still large when compared with observed datasets, with the average RMSE of FDAP and original TRMM data are 163.98 and $147.40 \mathrm{~mm}$, respectively (Table 2). The CFDAP had a lower error than FDAP and original annual TRMM precipitation, both for 2010 and for the average of ten years (Figure 10). The average RMSE of CFDAP decreased about 66.48 and $83.07 \mathrm{~mm}$ than that of FDAP and original TRMM data from 2006 to 2015. Additionally, the distribution of precipitation also changed, with the main trend still showing a gradual increase from southwest to northeast, but exhibiting a notable increase in 
precipitation in the high-elevation area, where the total amount of precipitation is roughly the same as some observed points in Laohugou No.12 Glacier [41], August-one Glacier [42].

Table 2. Validation results for downscaling of 2006-2015 annual precipitation at six measurement points.

\begin{tabular}{cccccccccccc}
\hline & & $\mathbf{2 0 0 6}$ & $\mathbf{2 0 0 7}$ & $\mathbf{2 0 0 8}$ & $\mathbf{2 0 0 9}$ & $\mathbf{2 0 1 0}$ & $\mathbf{2 0 1 1}$ & $\mathbf{2 0 1 2}$ & $\mathbf{2 0 1 3}$ & $\mathbf{2 0 1 4}$ & $\mathbf{2 0 1 5}$ \\
\hline & $\mathrm{RMSE}$ & 176.61 & 191.68 & 164.59 & 144.59 & 128.57 & 147.63 & 153.11 & 115.87 & 241.16 & 176.01 \\
Original & $\mathrm{B}$ & 0.06 & -0.07 & 0.10 & 0.14 & -0.08 & 0.11 & 0.08 & -0.06 & 0.41 & 0.23 \\
TRMM & $\mathrm{NSE}$ & 0.01 & -0.29 & 0.41 & 0.42 & 0.30 & 0.42 & 0.37 & 0.69 & 0.05 & 0.27 \\
& $\mathrm{R}^{2}$ & 0.30 & 0.26 & 0.48 & 0.51 & 0.30 & 0.44 & 0.40 & 0.76 & 0.46 & 0.46 \\
\hline & $\mathrm{RMSE}$ & 140.75 & 141.11 & 146.52 & 133.99 & 122.73 & 132.00 & 146.82 & 123.58 & 213.76 & 172.76 \\
FDAP & $\mathrm{B}$ & 0.05 & -0.08 & 0.13 & 0.17 & -0.03 & 0.15 & 0.10 & 0.16 & 0.38 & 0.21 \\
& $\mathrm{NSE}$ & 0.37 & 0.30 & 0.54 & 0.50 & 0.36 & 0.54 & 0.42 & 0.65 & 0.25 & 0.29 \\
& $\mathrm{R}$ & 0.44 & 0.45 & 0.61 & 0.66 & 0.43 & 0.43 & 0.47 & 0.78 & 0.68 & 0.46 \\
\hline & $\mathrm{RMSE}$ & 40.71 & 57.72 & 92.43 & 71.64 & 90.32 & 59.16 & 68.24 & 64.59 & 164.75 & 99.60 \\
CFDAP & $\mathrm{B}$ & 0.01 & -0.01 & 0.13 & 0.09 & -0.03 & 0.04 & 0.05 & -0.02 & 0.30 & 0.14 \\
& $\mathrm{NSE}$ & 0.95 & 0.88 & 0.82 & 0.86 & 0.65 & 0.91 & 0.87 & 0.90 & 0.55 & 0.77 \\
& $\mathrm{R}$ & 0.97 & 0.89 & 0.96 & 0.94 & 0.97 & 0.97 & 0.94 & 0.97 & 0.95 & 0.91 \\
\hline
\end{tabular}
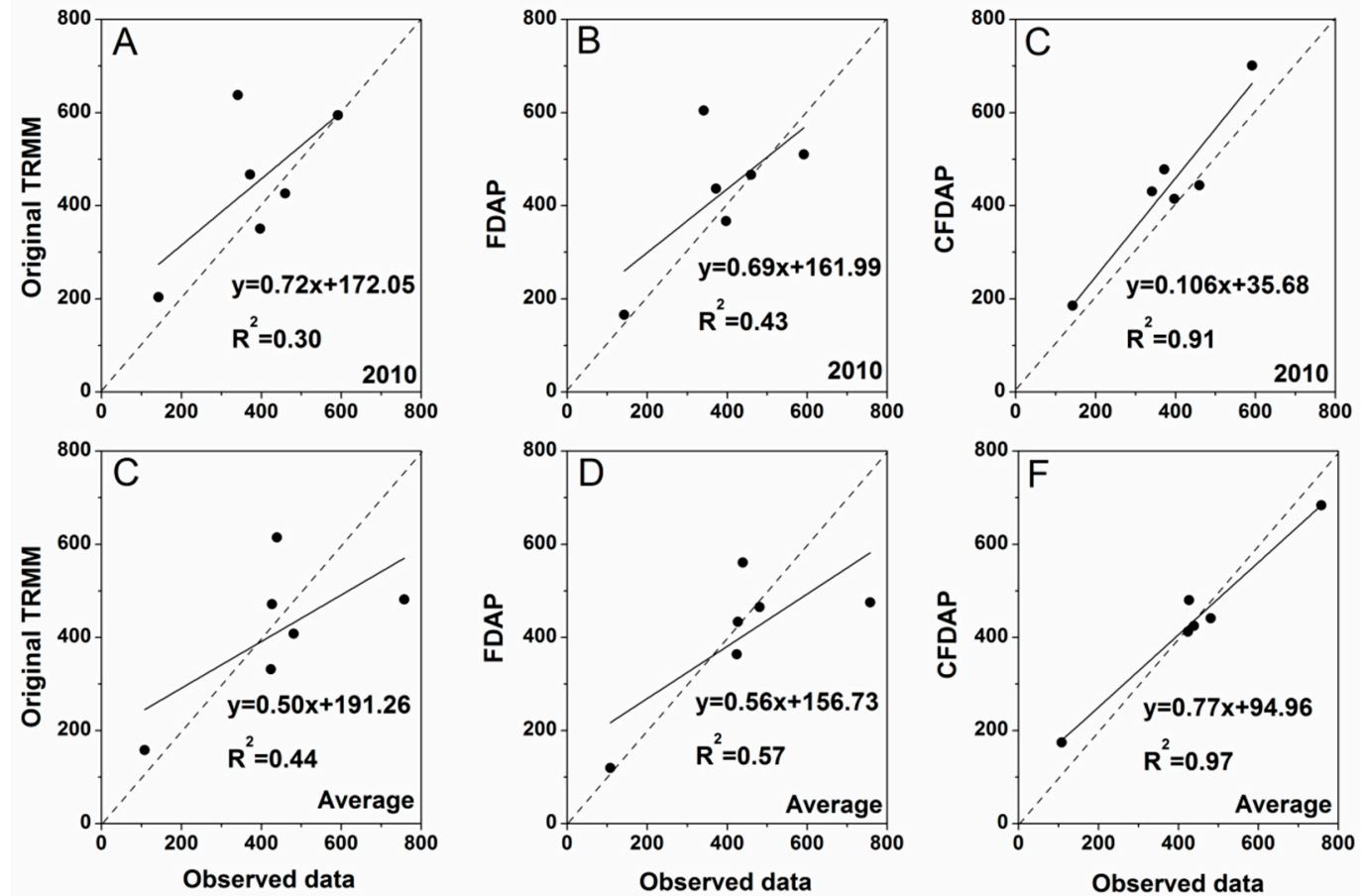

Figure 10. The scatter diagram between observed data (6 observation stations for validation) and original TRMM (A), FDAP (B), CFDAP (C) in 2010 and average of original TRMM (D), FDAP (E), CFDAP (F) (2006-2015).

To verify the effectiveness of the improved method, we used the original NDVI instead of PNDVI in the statistical model (4), and the parameters were obtained with statistical relationships. Compared with the previous downscaling method, which were based on the NDVI, DEM, longitude and latitude, the overall accuracy improved, though not for individual years. The accuracy of FDAP and CFDAP obtained with the improved downscaling method had better results, and the RMSE of downscaled results decreased from the previous method on average by $13.63 \mathrm{~mm}$ for FDAP and $80.11 \mathrm{~mm}$ for CFDAP, with higher NSE and $\mathrm{R}^{2}$ (Table 3). 
Table 3. Comparison of data accuracy between the improved method (this study) and the previous method.

\begin{tabular}{cccccccccccc}
\hline & & $\mathbf{2 0 0 6}$ & $\mathbf{2 0 0 7}$ & $\mathbf{2 0 0 8}$ & $\mathbf{2 0 0 9}$ & $\mathbf{2 0 1 0}$ & $\mathbf{2 0 1 1}$ & $\mathbf{2 0 1 2}$ & $\mathbf{2 0 1 3}$ & $\mathbf{2 0 1 4}$ & $\mathbf{2 0 1 5}$ \\
\hline & $\mathrm{RMSE}$ & 130.81 & 153.58 & 147.69 & 121.88 & 100.37 & 138.82 & 152.82 & 144.56 & 253.06 & 266.73 \\
Previous & $\mathrm{B}$ & 0 & 0.2 & 0.03 & 0.01 & 0.14 & -0.09 & -0.14 & -0.13 & -0.24 & -0.29 \\
method & $\mathrm{NSE}$ & 0.52 & 0.19 & 0.5 & 0.58 & 0.49 & 0.5 & 0.31 & 0.45 & 0.02 & -0.16 \\
& $\mathrm{R}^{2}$ & 0.52 & 0.48 & 0.5 & 0.59 & 0.65 & 0.56 & 0.5 & 0.61 & 0.4 & 0.36 \\
\hline \multirow{2}{*}{ Improved } & $\mathrm{RMSE}$ & 140.75 & 141.11 & 146.52 & 133.99 & 122.73 & 132 & 146.82 & 123.58 & 213.76 & 172.76 \\
methods & $\mathrm{B}$ & 0.05 & -0.08 & 0.13 & 0.17 & -0.03 & 0.15 & 0.1 & 0.16 & 0.38 & 0.21 \\
FDAP & $\mathrm{NSE}$ & 0.37 & 0.3 & 0.54 & 0.5 & 0.36 & 0.54 & 0.42 & 0.65 & 0.25 & 0.29 \\
& $\mathrm{R}$ & 0.44 & 0.45 & 0.61 & 0.66 & 0.43 & 0.43 & 0.47 & 0.78 & 0.68 & 0.46 \\
\hline Improved & $\mathrm{B}$ & 0.01 & -0.01 & 0.13 & 0.09 & -0.03 & 0.04 & 0.05 & -0.02 & 0.3 & 0.14 \\
methods & $\mathrm{RSE}$ & 40.71 & 57.72 & 92.43 & 71.64 & 90.32 & 59.16 & 68.24 & 64.59 & 164.75 & 99.6 \\
CFDAP & $\mathrm{NSE}$ & 0.95 & 0.88 & 0.82 & 0.86 & 0.65 & 0.91 & 0.87 & 0.9 & 0.55 & 0.77 \\
& $\mathrm{R}$ & 0.97 & 0.89 & 0.96 & 0.94 & 0.97 & 0.97 & 0.94 & 0.97 & 0.95 & 0.91 \\
\hline
\end{tabular}

\subsection{Downscaled Monthly Precipitation and Validation}

The overall spatial pattern of the PMR and CMR was same, but the CMR was noticeably lower than the PMR in August, 2010 (Figure 8). The original August TRMM data significantly overestimated observed precipitation (Figure 11). Monthly data from CMR were more closely aligned with the observed data. The improved method based on the previous research [25] was applied to obtain the monthly downscaled precipitation at $1000 \mathrm{~m}$ scale. The corrected monthly precipitation from CMR, with a maximum of $177.25 \mathrm{~mm}$ and an average of $58.94 \mathrm{~mm}$ in August, 2010, were lower than corresponding values for August precipitation from PMR, at 211.50 and $74.88 \mathrm{~mm}$, respectively (Figure 9). Although the results obtained with the two methods exhibited a large error compared with observation data, corrected results were more accurate than those calculated directly with the PMR, especially for the wet season (May-October) (Table 4). In the wet season, the average RMSE and B were less than $8.20 \mathrm{~mm}$ and 0.11, and the average RMSE and B were less than $4.93 \mathrm{~mm}$ and 0.5 , respectively, each month than those before the correction (Table 4). The corrected values, with higher accuracy, were closer to the observed data, especially in the Qilian, and Dachaidan stations (Figure 11). Correction of the extreme value produced by TRMM resulted in more accurate results.

Table 4. Validation monthly results for downscaling of precipitation at six measurement points.

\begin{tabular}{|c|c|c|c|c|c|c|c|c|c|c|c|c|c|}
\hline & & Jan. & Feb. & Mar. & Apr. & May. & Jun. & Jul. & Aug. & Sept. & Oct. & Nov. & Dec. \\
\hline \multirow{3}{*}{$\begin{array}{c}\text { Monthly } \\
\text { data by PMR }\end{array}$} & B & & & & & & & & 0.11 & & & & 1.74 \\
\hline & RMSE & 4.34 & 4.94 & 8.01 & 13.26 & 23.26 & 28.98 & 31.07 & 32.48 & 26.06 & 11.36 & 7.53 & 4.98 \\
\hline & NSE & -0.17 & -0.09 & -0.14 & 0.09 & 0.17 & 0.16 & 0.41 & 0.50 & 0.32 & 0.75 & -0.12 & -0.07 \\
\hline \multirow{3}{*}{$\begin{array}{c}\text { Monthly } \\
\text { data by CMR }\end{array}$} & B & 28 & 0.19 & 0.20 & 0.00 & & 0.00 & -0.10 & 0.02 & 0.0 & & & 0.12 \\
\hline & RMSE & 4.54 & 4.12 & 5.16 & 8.70 & 12.85 & 13.56 & 25.84 & 30.44 & 14.55 & 6.80 & 6.28 & 4.21 \\
\hline & NSE & -0.24 & 0.23 & 0.44 & 0.17 & 0.66 & 0.75 & 0.39 & 0.55 & 0.77 & 0.90 & 0.14 & 0.21 \\
\hline
\end{tabular}



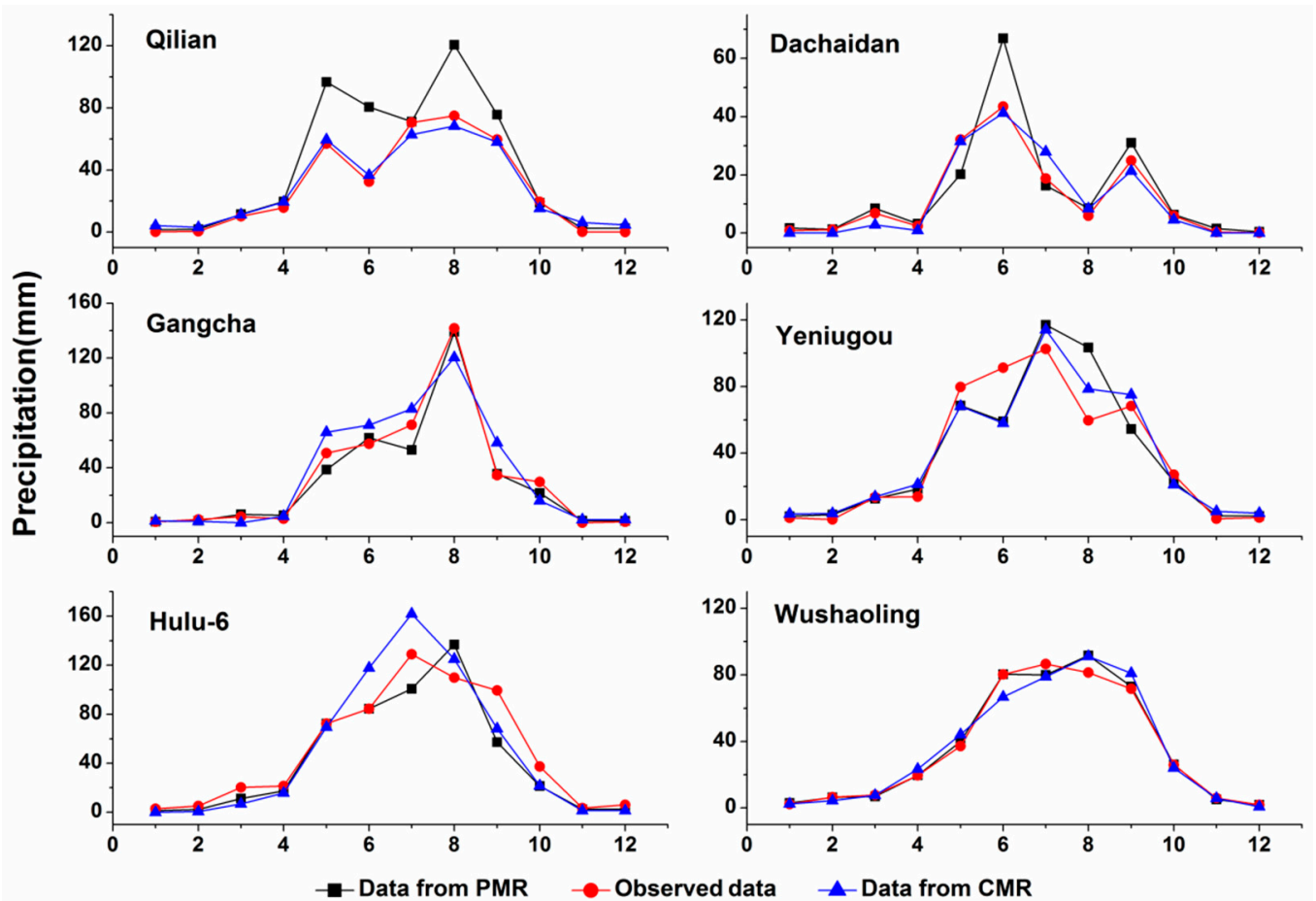

Figure 11. Comparison of observed with data from PMR and CMR at a monthly scale (2006-2015).

\subsection{Error Analysis of Downscaled Precipitation}

The statistical downscaling models are based on three hypotheses: 1) There is a significant correlation between precipitation at large scale and variables at regional scale, 2) precipitation at large scale can be well simulated with statistical models, and 3) statistical relationships are valid in a changing environment [43]. First, there is no theoretical basis for the methodology of applying other variables to calculate precipitation, and it is based only on the correlation between independent and dependent variables. Second, the response error may be generated in the process of applying high resolution variables to low resolution variables. Third, variables change with the environment, and statistical relationships do not remain stable across regions. Therefore, systematic errors are inevitably generated when a statistical model is extended beyond the original study area, or used to calculate precipitation with high precision variables.

The accuracy of the various variables used in statistical models could affect the downscaled results, such as the NDVI. The NDVI is calculated from remotely-sensed imagery, the capture of which may be affected by terrain, cloud cover, and other factors, producing errors. Similarly, errors may also occur in the processes of generating and resampling DEM.

The accuracy of original TRMM may be a key factor which affected the downscaled results. The errors in the downscaled results were investigated. The $\mathrm{R}^{2}$ between the observed data and data used for validation was used to represent accuracy. The accuracy of the original coarse TRMM, CRU, ERA, and the FDAP (including TRMM, CRU and ERA), and CFDAP (including TRMM, CRU and ERA) was compared, respectively. The accuracy of the original data was well correlated with that of FDAP datasets, but the accuracy of CFDAP datasets had little correlation with that of the original data (Figure 12). That is, original data accuracy did not affect CFDAP, but it had an effect on FDAP, regardless of whether TRMM, CRU, or ERA. In addition, Ren [44] used the geographically-weighted regression method to compare the downscaling results of TRMM and GPM in the Shaanxi Qinba Mountains. Although the spatial resolution GPM is higher, the TRMM downscaled results are more accurate, which same as in Yellow River Basin [45]. Ceccherini et al. [46] used multiple linear regression to downscale different precipitation products, and the results show that TRMM and CHIRPS get reasonably good results; conversely RFE (RainFall Estimate, $0.1^{\circ} \times 0.1^{\circ}$ ) and CMORPH (Climate prediction center 
MORPHing technique, $0.25^{\circ} \times 0.25^{\circ}$ ) have among the highest errors in western Africa. Therefore, the spatial resolution may be not the key factor affecting the accuracy of downscaled results.
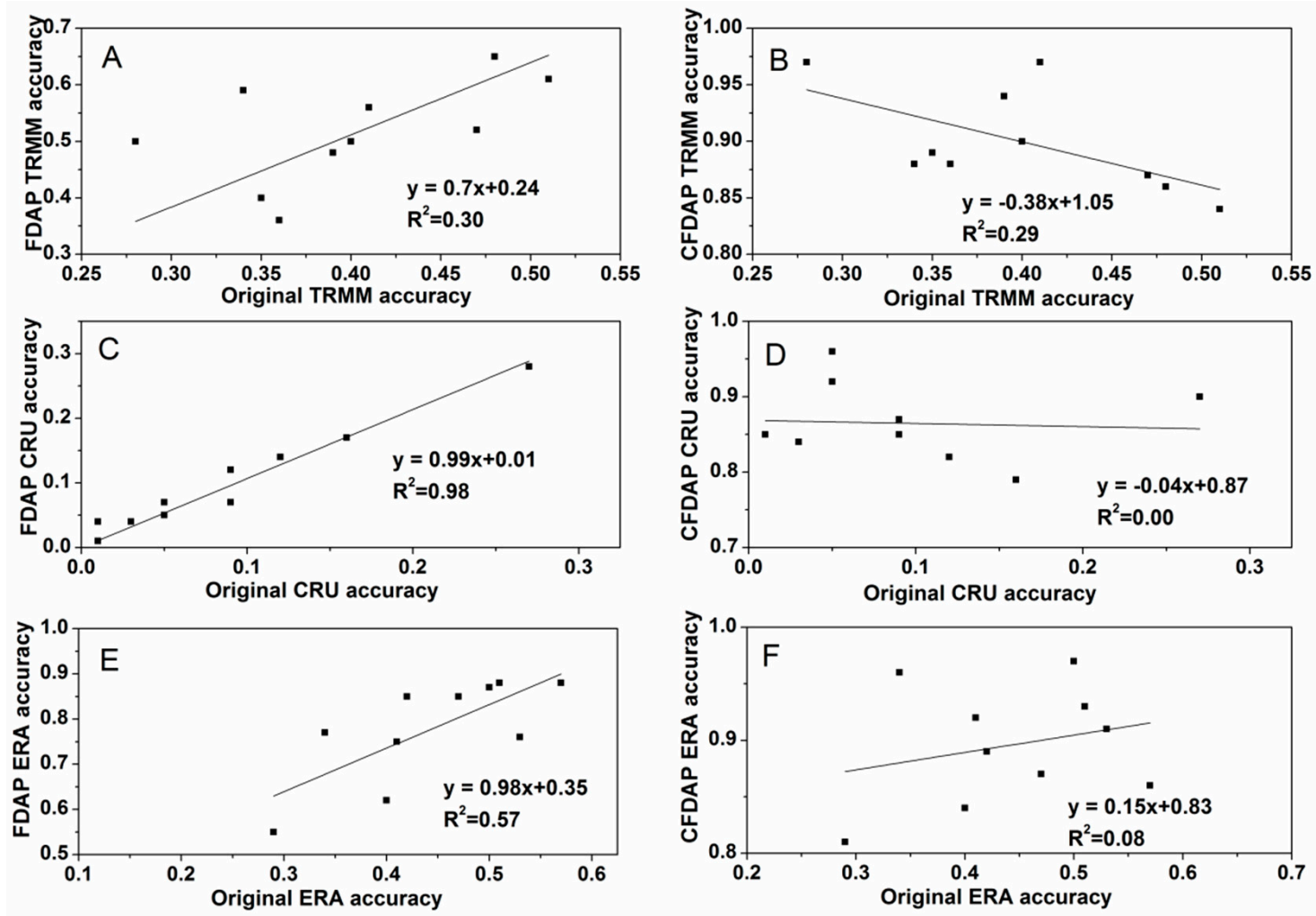

Figure 12. Data accuracy $\left(R^{2}\right)$ scatter diagram between original (TRMM, CRU, ERA) and FDAP (TRMM, CRU, ERA) or CFDAP data (TRMM, CRU, ERA).

Moreover, errors also occur in the correction process. Due to uneven distribution of rain gauges in mountainous areas, the accuracy of CFDAP data was higher where rain gauges were concentrated than where rain gauges were sparse. More importantly, the few rain gauges at high elevations resulted in an error in estimating precipitation at high elevation (Figure 1).

In summary, the accuracy of downscaled results may be due to three important factors: first, the ability of the regression models to explain satellite-derived precipitation data, second, the accuracy of original satellite precipitation datasets [8,9], third, the distribution of rainfall observations points for correction, including the distribution at different elevations.

\section{Discussion}

\subsection{The Advantages and Disadvantages of the Model}

Various studies indicated that the distribution of NDVI is influenced by a combination of hydrologic and thermal conditions $[23,24]$. In mountainous areas, temperature becomes the main factor affecting the distribution of NDVI above certain elevations [23,24]. It is not feasible to consider the relationship between precipitation and NDVI in a downscaling process in alpine environments. Therefore, the thermal effect must be eliminated from the modeling of the relationships between precipitation and NDVI.

The spatial distribution of precipitation cannot be simulated accurately with NDVI and elevation alone. In the Qilian Mountains of northwest China, precipitation is influenced by different sources of water vapor, and the distribution of precipitation and water vapor from east to west, and north to south are quite different $[27,28]$. Simulation models use longitude and latitude to represent the distance between the study area and the source of water vapor; this can represent the spatial distribution 
of precipitation in mountainous areas. Our results showed that it was more accurate to simulate precipitation with NDVI, DEM, longitude, and latitude than with the downscaled results obtained with NDVI and DEM only.

In addition, statistical models have some limitations. First, the NDVI-based satellite downscaled method cannot be applied in regions where NDVI is not affected by precipitation, such as in urban and desert areas. Consequently, understanding the distribution of precipitation in these areas still depends on different interpolation methods and on-the-ground meteorological observations. Second, study areas where water does not restrict plant growth, such as in the rainforest, NDVI is not suitable for application in the models. Third, previous downscaling research was based on the assumption that precipitation was significantly correlated with NDVI or/and DEM in various regions $[9,10,15,47-51]$. It is widely acknowledged that the response of vegetation to precipitation and temperature usually lags by about two or three months in different regions and at high elevations in mountainous areas $[52,53]$. Therefore, the response lags result in unreliable precipitation-PNDVI relationships at monthly scales, and the precipitation-NDVI relationships may be better than precipitation-PNDVI relationships $[14,15,18,54]$. Consequently, PNDVI is not suitable for downscaling studies at monthly scales because of the differences in plant-growth lag in different regions and different elevations.

\subsection{Necessity for and Feasibility of Corrected Downscaled Data}

The downscaling methodology described in this paper is based on the coarse annual TRMM data to obtain high resolution $(\sim 1000 \mathrm{~m})$ annual precipitation data. However, coarse TRMM datasets are not accurate compared with observed data (Table 2). Although the final downscaling results are corrected with residuals, this method corrected the systematic error of statistical downscaling model. The residuals in the downscaling process are that portion of precipitation amount that the downscaling models cannot simulate [8,9]. These are not the residuals between the original TRMM data (or predicted results) and observed precipitation. Therefore, the final downscaled results reduce the spatial resolution of the original annual TRMM data, but do not effectively improve TRMM data accuracy. Consequently, the spatial pattern of final downscaled results obtained with this method is very similar to that of the original TRMM data (Figures 6A and 7A). In Figure 5, the distribution of residuals is the same as the distribution of precipitation, and the spatial pattern of residuals is the manifestation of spatial heterogeneity. Therefore, the residuals between the observed and the final downscaled data also need a spatial correction, and that is why elevation, longitude, and latitude were introduced into the formula for both the corrected final downscaled results and the corrected monthly precipitation ratio.

\subsection{The Future of Downscaling Research}

Further research on downscaling based on satellite products should include the following: (1) Other land surface characteristics (soil moisture, evapotranspiration), and meteorological conditions prior to precipitation (humidity, atmospheric circulation, and cloud amount), (2) adding high elevation observation data to provide the basis for calibration and validation of downscaling results, (3) developing of new sensors to address solid precipitation in next-generation satellite products, particularly for light rainfall and cold-season solid precipitation [55], (4) exploring disaggregation analysis [25] to derive monthly precipitation estimates based on the annual results generated in this study, and developing additional spatial downscaling algorithms, especially for downscaling of coarse-resolution satellite-based precipitation estimates at higher temporal resolutions (e.g., daily, weekly, or monthly) [14].

\section{Conclusions}

In this study, we aimed to improve a model to obtain the downscaled annual and monthly precipitation datasets. We concluded from the analysis that: 
(1) The correlation between precipitation and PNDVI was higher than the correlation between precipitation and NDVI.

(2) The accuracy of FDAP and CFDAP in the improved method was higher than that of the downscaled data obtained from the previous method which was based on relationships between precipitation and NDVI, DEM, longitude, and latitude. The RMSE of precipitation decreased on average by 13.63 and $80.11 \mathrm{~mm}$, respectively, for FDAP and CFDAP.

(3) The accuracy of CFDAP was significantly higher than that of FDAP based solely on land surface characteristics. Average RMSE from 2006 to 2015 of the corrected downscaled dataset was 66.48 and $83.07 \mathrm{~mm}$ less than that of the downscaled results without correction $(80.91 \mathrm{vs} .147 .39 \mathrm{~mm})$ and original TRMM data ( $80.91 \mathrm{vs.} 163.98 \mathrm{~mm}$ ).

(4) The accuracy of the original satellite data affected FDAP results but had no significant effects on CFDAP results.

(5) Monthly precipitation obtained with the CMR was higher than that obtained with the PMR. The average RMSE of the former was $4.93 \mathrm{~mm}$ lower each month than that of the latter (11.42 vs. $16.35 \mathrm{~mm})$.

Author Contributions: Conceptualization, L.W. and R.C.; data curation, G.L. and S.G.; funding acquisition, R.C.; investigation, L.W. and R.C.; methodology, L.W. and R.C.; validation, L.W.; visualization, L.W.; writing—original draft, L.W.; writing—review \& editing, L.W., R.C., C.H., Y.Y., J.L., Z.L. and X.W.

Funding: This research was funded by the National Natural Sciences Foundation of China (Grant number: 41690141, 41671029, 41501040), and the STS program of Chinese Academy of Sciences (Grant number: HHS-TSS-STS-1503). The APC was funded by 41690141, 41671029, 41501040 and HHS-TSS-STS-1503.

Acknowledgments: Thanks to Kathryn B. Piatek for her editorial suggestions on the spelling and grammar of manuscripts.

Conflicts of Interest: The authors declare no conflict of interest.

\section{References}

1. Sevruk, B. Regional dependency of precipitation-altitude relationship in the Swiss Alps. In Climatic Change at High Elevation Sites; Springer: Dordrecht, The Netherlands, 1997; pp. 123-137.

2. Bhatt, B.C.; Nakamura, K. Characteristics of monsoon rainfall around the Himalayas revealed by TRMM precipitation radar. Mon. Weather Rev. 2005, 133, 149-165. [CrossRef]

3. Daly, C.; Smith, J.W.; Smith, J.I.; McKane, R.B. High-resolution spatial modeling of daily weather elements for a catchment in the Oregon Cascade Mountains, United States. J. Appl. Meteorol. Climatol. 2007, 46, 1565-1586. [CrossRef]

4. Joyce, R.J.; Janowiak, J.E.; Arkin, P.A.; Xie, P.P. CMORPH: A method that produces global precipitation estimates from passive microwave and infrared data at high spatial and temporal resolution. J. Hydrometeorol. 2004, 5, 487-503. [CrossRef]

5. Michaelides, S.; Levizzani, V.; Anagnostou, E.; Bauer, P.; Kasparis, T.; Lane, J.E. Precipitation: Measurement, remote sensing, climatology and modeling. Atmos. Res. 2009, 94, 512-533. [CrossRef]

6. Guo, J.; Liang, X.; Leung, L.R. Impacts of different precipitation data sources on water budgets. J. Hydrol. 2004, 298, 311-334. [CrossRef]

7. Smith, M.B.; Koren, V.I.; Zhang, Z.; Reed, S.M.; Pan, J.J.; Moreda, F. Runoff response to spatial variability in precipitation: An analysis of observed data. J. Hydrol. 2004, 298, 267-286. [CrossRef]

8. Immerzeel, W.W.; Rutten, M.M.; Droogers, P. Spatial downscaling of TRMM precipitation using vegetative response on the Iberian Peninsula. Remote Sens. Environ. 2009, 113, 362-370. [CrossRef]

9. Jia, S.; Zhu, W.; Lú, A.; Yan, T. A statistical spatial downscaling algorithm of TRMM precipitation based on NDVI and DEM in the Qaidam Basin of China. Remote Sens. Environ. 2011, 115, 3069-3079. [CrossRef]

10. Retalis, A.; Tymvios, F.; Katsanos, D.; Michaelides, S. Downscaling CHIRPS precipitation data: An artificial neural network modelling approach. Int. J. Remote. Sens. 2017, 38, 3943-3959. [CrossRef] 
11. Zhang, T.; Li, B.; Yuan, Y.; Gao, X.; Sun, Q.; Xu, L.; Jiang, Y. Spatial downscaling of TRMM precipitation data considering the impacts of macro-geographical factors and local elevation in the Three-River Headwaters Region. Remote Sens. Environ. 2018, 215, 109-127. [CrossRef]

12. Alexakis, D.D.; Tsanis, I.K. Comparison of multiple linear regression and artificial neural network models for downscaling TRMM precipitation products using MODIS data. Environ. Earth Sci. 2004, 75, 1077. [CrossRef]

13. Chen, C.; Zhao, S.; Duan, Z.; Qin, Z. An improved spatial downscaling procedure for TRMM 3B43 precipitation product using geographically weighted regression. IEEE J. Sel. Top. Appl. Earth Obs. Remote Sens. 2015, 8, 4592-4604. [CrossRef]

14. Xu, S.; Wu, C.; Wang, L.; Gonsamo, A.; Shen, Y.; Niu, Z. A new satellite-based monthly precipitation downscaling algorithm with non-stationary relationship between precipitation and land surface characteristics. Remote Sens. Environ. 2015, 162, 119-140. [CrossRef]

15. Zhan, C.; Han, J.; Hu, S.; Liu, L.; Dong, Y. Spatial Downscaling of GPM Annual and Monthly Precipitation Using Regression-Based Algorithms in a Mountainous Area. Adv. Meteorol. 2018, 2018, 1-13. [CrossRef]

16. Jing, W.; Yang, Y.; Yue, X.; Zhao, X. A spatial downscaling algorithm for satellite-based precipitation over the Tibetan plateau based on NDVI, DEM, and land surface temperature. Remote Sens. 2016, 8, 655. [CrossRef]

17. Ma, Z.; Shi, Z.; Zhou, Y.; Xu, J.; Yu, W.; Yang, Y. A spatial data mining algorithm for downscaling TMPA 3B43 V7 data over the Qinghai-Tibet Plateau with the effects of systematic anomalies removed. Remote Sens. Environ. 2017, 200, 378-395. [CrossRef]

18. Chen, Y.; Huang, J.; Sheng, S.; Mansaray, L.R.; Liu, Z.; Wu, H.; Wang, X. A new downscaling-integration framework for high-resolution monthly precipitation estimates: Combining rain gauge observations, satellite-derived precipitation data and geographical ancillary data. Remote Sens Environ. 2018, 214, 154-172. [CrossRef]

19. Liu, X.; Zhang, M.; Wang, S.; Wang, J.; Zhao, P.; Zhou, P. Assessment of diurnal variation of summer precipitation over the Qilian Mountains based on an hourly merged dataset from 2008 to 2014. J. Geogr. Sci. 2017, 27, 326-336. [CrossRef]

20. Chen, H.; Li, Y.; Yang, Z.; Shen, Z. Research on the Relationship Between Terrain Factors and Precipitation. Res. Soil Water Conserv. 2007, 14, 119-122.

21. Duan, L.; Fan, K.; Li, W.; Liu, T. Spatial downscaling algorithm of TRMM precipitation based on multiple high-resolution satellite data for Inner Mongolia, China. Theor. Appl. Climatol. 2007, 135, 15-59. [CrossRef]

22. Liu, J.; Zhang, W.; Nie, N. Spatial Downscaling of TRMM Precipitation Data Using an Optimal Subset Regression Model with NDVI and Terrain Factors in the Yarlung Zangbo River Basin, China. Adv. Meteorol. 2018, 2018, 1-13. [CrossRef]

23. Hu, G.; Jin, X.; Wang, L.; Cai, X. The relationship between vegetation growth and the combination of water and heat in the Qilian Mountains. J. Arid Land Resour. Environ. 2009, 23, 17-20.

24. Wang, J.; Chang, X.; Ge, S.; Miao, Y.; Chang, Z.; Zhang, H. Vertical distribution of vegetation and water and heat conditions of Qilian Mountains (Northern slope). J. Northw. For. Univ. 2001, 16, 1-3.

25. Duan, Z.; Bastiaanssen, W.G.M. First results from Version 7 TRMM 3B43 precipitation product in combination with a new downscaling-calibration procedure. Remote Sens. Environ. 2013, 131, 1-13. [CrossRef]

26. McVicar, T.R.; Körner, C. On the use of elevation, altitude, and height in the ecological and climatological literature. Oecologia 2013, 171, 335-337. [CrossRef]

27. Zhang, Q.; Yu, Y.X.; Zhang, J. Characteristics of water cycle in the Qilian Mountains and the oases in Hexi inland river basins. J. Glaciol. Geocryol. 2008, 30, 907-913.

28. Xu, J.J.; Wang, K.L.; Jiang, H.; Li, Z.G.; Sun, J.; Luo, X.P.; Zhu, Q.L. A numerical simulation of the effects of Westerly and Monsoon on precipitation in the Heihe River basin. J. Glaciol. Geocryol. 2010, 32, 489-496.

29. Chen, R.; Han, C.; Liu, J.; Yang, Y.; Liu, Z.; Wang, L.; Kang, E. Maximum precipitation altitude on the northern flank of the Qilian Mountains, northwest China. Hydrol. Res. 2018, 49, 1696-1710. [CrossRef]

30. Li, Y. Study and Analysis of Climate Characteristics of Precipitation and Its Causes over Qilian Mountains. Ph.D. Thesis, Lanzhou University, Lanzhou, China, 2008.

31. Xu, J.; Zhang, B.; Zhu, Y.; Sun, R. Distribution and geographical analysis of altitudinal belts in the Altun Qilian Mountains. Geogr. Res. 2006, 25, 977-985.

32. Tian, Q.; He, Z.; Xiao, S.; Du, J.; Peng, X.; Chen, L.; Lin, P.; Zhu, X.; Ding, A. Growing Season Stem Water Status Assessment of Qinghai Spruce through the Sap Flow and Stem Radial Variations in the Qilian Mountains of China. Forests 2018, 9, 2. [CrossRef] 
33. Jain, Y.K.; Bhandare, S.K. Min max normalization based data perturbation method for privacy protection. Int. J. Comput. Commun. Technol. 2011, 2, 45-50.

34. Holben, B.N. Characteristics of maximum-value composite images from temporal AVHRR data. Int. J. Remote Sens. 1986, 7, 1417-1434. [CrossRef]

35. Agam, N.; Kustas, W.P.; Anderson, M.C.; Li, F.; Neale, C.M.U. A vegetation index based technique for spatial sharpening of thermal imagery. Remote Sens. Environ. 2007, 107, 545-558. [CrossRef]

36. Lin, Z. Orographic Precipitation Climatology; Science Press: Beijing, China, 1995; pp. 6-45.

37. Ichii, K.; Kawabata, A.; Yamaguchi, Y. Global correlation analysis for NDVI and climatic variables and NDVI trends: 1982-1990. Int. J. Remote Sens. 2002, 23, 3873-3878. [CrossRef]

38. Sun, P.S.; Liu, S.R.; Jiang, H.; Lu, Y.L.; Liu, J.T.; Lin, Y.; Liu, X. Hydrologic effects of NDVI time series in a context of climatic variability in an upstream catchment of the Minjiang River. J. Am. Water Resour. Assoc. 2008, 44, 1132-1143. [CrossRef]

39. Wang, N.; He, J.; Jiang, X.; Song, G.; Pu, J.; Wu, X.; Chen, L. Study on the zone of maximum precipitation in the north slope of the central Qilian Mountains. J. Glaciol. Geocryol. 2009, 31, 395-403.

40. Wang, L.; Chen, R.; Song, Y.; Yang, Y.; Liu, J.; Han, C.; Liu, Z. Precipitation-altitude relationships on different timescales and at different precipitation magnitudes in the Qilian Mountains. Theor. Appl. Climatol. 2018, 134, 875-884. [CrossRef]

41. Sun, W.; Qin, X.; Du, W.; Liu, W.; Liu, Y.; Zhang, T.; Xu, Y.; Zhao, Q.; Wu, J.; Ren, J. Ablation modeling and surface energy budget in the ablation zone of Laohugou glacier No. 12, western Qilian mountains, China. Ann. Glaciol. 2014, 55, 111-120. [CrossRef]

42. Guo, S.; Chen, R.; Liu, G.; Han, C.; Song, Y.; Liu, J.; Yang, Y.; Liu, Z.; Wang, X.; Liu, X.; et al. Simple parameterization of aerodynamic roughness lengths and the turbulent heat fluxes at the top of midlatitude August-one glacier, Qilian Mountains, China. J. Geophys. Res. Atmos. 2018, 123, 12-066. [CrossRef]

43. Fan, L.; Fu, C.; Chen, D. Review on creating future climate change scenarios by statistical downscaling techniques. Adv. Earth Sci. 2015, 20, 320-329.

44. Ren, L. Downscaling Research on Multi-source Remote Sensing Precipitation Data in Qinba Mountainous Area of Shaanxi Province; Shaanxi Normal University: Shaanxi, China, 2018.

45. Dong, G.; Fan, D.; Yang, T.; Xu, H.; Zhou, J.; Dang, S.; Cheng, C. Analysis on the Applicability of GPM and TRMM Precipitation Data in the Yellow River Basin. Res Soil Water Conserv. 2018, 25, 81-87.

46. Ceccherini, G.; Ameztoy, I.; Hernández, C.; Moreno, C. High-resolution precipitation datasets in South America and West Africa based on satellite-derived rainfall, enhanced vegetation index and digital elevation model. Remote Sens. 2015, 7, 6454-6488. [CrossRef]

47. Zhang, Q.; Shi, P.; Singh, V.P.; Fan, K.; Huang, J. Spatial downscaling of TRMM-based precipitation data using vegetative response in Xinjiang, China. Int. J. Climatol. 2017, 37, 3895-3909. [CrossRef]

48. Ma, Z.; Zhou, Y.; Hu, B.; Liang, Z.; Shi, Z. Downscaling annual precipitation with TMPA and land surface characteristics in China. Int. J. Climatol. 2017, 37, 5107-5119. [CrossRef]

49. Sharifi, E.; Saghafian, B.; Steinacker, R. Downscaling Satellite Precipitation Estimates with Multiple Linear Regression, Artificial Neural Networks and Spline Interpolation Techniques. J. Geophys. Res. Atmos. 2019, 124, 789-805. [CrossRef]

50. Shi, Y.; Song, L.; Xia, Z.; Lin, Y.; Myneni, R.; Choi, S.; Wang, L.; Ni, X.; Lao, C.; Yang, F. Mapping annual precipitation across mainland China in the period 2001-2010 from TRMM3B43 product using spatial downscaling approach. Remote Sens. 2015, 7, 5849-5878. [CrossRef]

51. Zhang, Y.; Li, Y.; Ji, X.; Luo, X.; Li, X. Fine-Resolution Precipitation Mapping in a Mountainous Watershed: Geostatistical Downscaling of TRMM Products Based on Environmental Variables. Remote Sens. 2018, 10, 119. [CrossRef]

52. Xu, X.; Lin, Z.; Xue, F.; Zeng, Q. Correlation analysis between meteorological factors and the ratio of vegetation cover. Acta Ecol. Sin. 2003, 23, 221-230.

53. Chuai, X.W.; Huang, X.J.; Wang, W.J.; Bao, G. NDVI, temperature and precipitation changes and their relationships with different vegetation types during 1998-2007 in Inner Mongolia, China. Int. J. Climatol. 2013, 33, 1696-1706. [CrossRef] 
54. Jing, W.; Yang, Y.; Yue, X.; Zhao, X. A comparison of different regression algorithms for downscaling monthly satellite-based precipitation over North China. Remote Sens. 2016, 8, 835. [CrossRef]

55. Hou, A.Y.; Kakar, R.K.; Neeck, S.; Azarbarzin, A.A.; Kummerow, C.D.; Kojima, M.; Oki, R.; Nakamura, K.; Iguchi, T. The global precipitation measurement mission. Bull. Am. Meteorol. Soc. 2004, 95, 701-722. [CrossRef]

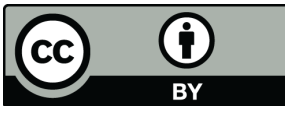

(C) 2019 by the authors. Licensee MDPI, Basel, Switzerland. This article is an open access article distributed under the terms and conditions of the Creative Commons Attribution (CC BY) license (http://creativecommons.org/licenses/by/4.0/). 